\title{
Changes in visual acuity from 4 to 12 years of age in children operated for bilateral congenital cataracts
}

\section{G Magnusson, M Abrahamsson, J Siöstrand}

Br J Ophthalmol 2002;86:1385-1389

See end of article for authors' affiliations

\section{Correspondence to:} Gunilla Magnusson, MD, Göteborg University, Department of

Ophthalmology,

SU/Mölndal, S-431 80

Göteborg, Sweden

gunilla.magnusson@oft.gu.se

Accepted for publication 11 June 2002

\begin{abstract}
Aims: To investigate the long term effects of age at surgery on the development of visual acuity (VA) by measuring VA from preschool age to puberty. Furthermore, to report the VA levels at 12 years of age in a geographically based cohort of operated congenital bilateral cataracts.

Methods: All children born in four western counties of Sweden between January 1980 and December 1993 who were diagnosed with congenital cataracts were included in a longitudinal prospective study. The monocular VA of the better eye in 38 subjects was analysed at $4,7,10$, and 12 years of age, with 20 total and 18 partial cataracts. The mean follow up time was 9.3 years after surgery. Results: The final value of VA was 0.4 or above for approximately $50 \%$ of the subjects at 12 years of age. Visual acuity improved to a considerable extent after school age, especially in children who underwent surgery between the ages of 7 weeks and 1 year. Results for partial cataracts were favourable compared to those for total cataracts, reaching a mean of approximately 0.5 at age 12 . The mean $V A$ in the group of total congenital cataracts operated on before 7 weeks of age achieved higher values of VA at 4 years of age compared to children with total cataracts operated on between 7 weeks and 1 year of age. However, no statistically significant difference in VA results among these groups could be proved.

Conclusion: Visual acuity improves to a considerable extent after school age in children with delayed visual development caused by congenital cataracts. Surgery within 7 weeks results in a more rapid development of VA, initially.
\end{abstract}

S ince the 1970s, when surgical techniques were improved and early surgery was introduced, management of congenital cataracts has resulted in normal or near normal visual development. ${ }^{1-8}$ Despite the increased chance of restored visual function after early surgery, in reality a complete visual rehabilitation is rarely obtained. ${ }^{9-17}$ Several studies on monocular cataracts prove a association between early surgery and normalised visual function, ${ }^{818} 19$ which implies reduced risk of unequal competition, ${ }^{20}$ and a critical period for surgical treatment within the first 6 weeks of life was proposed in 1996 by Birch and Stager. ${ }^{21}$ However, the literature is not as conclusive regarding the critical period in cases of bilateral cataracts and the relation between age at surgery and visual outcome (Table 1).

Normally, visual acuity improves rapidly in the first 6 months after birth and more gradually thereafter, reaching adult values at 4-6 years of age. ${ }^{22-24}$ Owing to visual deprivation in early infancy normal visual acuity (VA) development in children with congenital bilateral cataracts is disturbed. In order to improve management of congenital cataracts, as well as to understand the maturing process of the human visual system, ${ }^{25}$ evaluation of this disrupted or delayed visual development has been a subject of interest in the literature. ${ }^{1-6} 9^{11-17}$ However, it is difficult to interpret and compare these studies. Firstly, they do not provide a conclusive

Table 1 Summary of literature reports on congenital bilateral cataracts regarding relation between age at surgery and visual outcome

\begin{tabular}{|c|c|c|c|c|c|}
\hline Study & $\begin{array}{l}\text { Preferable age } \\
\text { at surgery }\end{array}$ & Comments on visual acuity (VA) & No & $\begin{array}{l}\text { Type of cataract } \\
\text { investigated }\end{array}$ & Population \\
\hline Rogers et $\left.a\right|^{5}$ & $<8$ weeks & $\begin{array}{l}\text { Surgery after the age of } 8 \text { weeks resulted in a substantial visual lag } \\
\text { within the first } 1.5 \text { years, compared to surgery before } 8 \text { weeks. }\end{array}$ & 7 & Total & Hospital based \\
\hline Gelbart et a ${ }^{\beta}$ & $<8$ weeks & $\begin{array}{l}\text { Children with the best visual outcome ( } 17 \text { individuals) were operated } \\
\text { on within the first } 8 \text { weeks of life, exhibiting a mean postoperative } \\
\text { VA of } 0.5 \\
\text { Those who underwent surgery between } 8 \text { and } 41 \text { weeks achieved } \\
\text { a mean postoperative VA of } 0.06 \text { ( } 7 \text { individuals). }\end{array}$ & 24 & Total and partial & Hospital based \\
\hline Schulz ${ }^{10}$ & $<6$ months & $\begin{array}{l}\text { VA increased up to school age (retarded development) when } \\
\text { operation occurred before the age of } 6 \text { months. }\end{array}$ & 8 & Total & Hospital based \\
\hline Lorenz and Wörle & $<1$ year & $\begin{array}{l}\text { Surgery before the age of } 1 \text { year resulted in normal VA development } \\
\text { until 18-24 months of age. }\end{array}$ & 29 & Total & Hospital based \\
\hline Kugelberg $^{4}$ & $<8$ weeks & $\begin{array}{l}\text { Surgery after the age of } 3 \text { months resulted in subnormal VA } \\
\text { ( } 7 \text { individuals). } \\
\text { Children who underwent surgery before } 2 \text { months of age ( } 7 \text { patients) } \\
\text { achieved almost normal VA development. }\end{array}$ & 14 & Total & Hospital based \\
\hline Wright et $a l^{12}$ & Not stated & $\begin{array}{l}\text { Surgery after the age of } 10 \text { months can result in VA as good as } 0.7 \\
\text { at the age of } 4 \text { years (total cataracts) and } 1.0 \text { for partial cataracts. }\end{array}$ & 47 & Total and partial & Hospital based \\
\hline
\end{tabular}


answer as to whether or not VA development is generally to be regarded as final at a specific age for patients with delayed visual development. This ambiguity results in the use of a final VA concept at various ages in different studies without taking into account the VA variability depending on age. Secondly, age at surgery is not the only important factor affecting VA development. Several studies contain a number of biases, such as the inclusion of various ages at onset of the visual defect, varying cataract morphology, and differing surgical techniques and ages at surgery. ${ }^{26}$

In many long term follow ups of postoperative VA results presented earlier in the literature, measurements have been reported from one separate occasion. ${ }^{6}{ }^{1327}$ Our study design permits evaluation of an individual's continuous VA developmental curve related to the ages at which the measurements were taken. To our knowledge, this type of VA analysis has been performed only once before by Schulz in 1990 on seven cases of total bilateral cataracts. ${ }^{10}$

The aim of this study was to investigate the long term effects of age at surgery on visual acuity development by measuring visual acuity between preschool age and puberty. Furthermore, it aimed to report the VA levels at 12 years of age in a geographically based cohort of operated congenital bilateral cataracts.

\section{METHODS}

All children born in four western counties in Sweden between January 1980 and December 1993 who were diagnosed with congenital bilateral cataracts were included in the study. The cataracts were presumed congenital when arising early with no distinct postnatal origin defined, taking a conservative view. The cataracts were divided into two subgroups, total and partial. The diagnosis of total required that the pupil area had to be totally covered by the cataract, without being dilated, and that no red reflex was obtained. In cases of one partial and one total cataract on each eye, the patient was defined as having partial cataract. Most of those needing surgery were operated on in the department of ophthalmology, Sahlgrenska University Hospital, and followed up by the senior author (JS) regarding visual outcome and postoperative complications. The mean follow up time was 9.3 years following surgery. In all cases of total cataract the surgery was performed within 3 days of the definitive diagnosis.

During the 1980s, surgery was mainly performed using aspiration techniques and vitreous cutting instruments. From approximately 1985, the majority of lensectomies performed during the first 12 months of age included a shallow anterior vitrectomy. During the early 1990s, the technique changed to phaco enhanced aspiration, and a more extensive anterior vitrectomy is now performed. Techniques for handling the posterior capsule also evolved over this period. During the early 1980s, when aspiration with a needle was used, the posterior capsule was left intact if it was perfectly clear; otherwise, an incision was made. When the vitreous cutter was used, the visible part of the posterior capsule was removed before the anterior vitrectomy was performed in all infants. During the 1990s, a technique using curvilinear capsulorhexis was introduced, and the anterior vitrectomy was performed thereafter in all cases, regardless of age. An intraocular lens was implanted at the time of cataract extraction in one case only. Secondary implantation was performed in eight children with partial cataracts. Most of the children with secondary implants underwent surgery after 1 year of age (7/8). The impact of secondary implantations on visual acuity was therefore presumed to be limited.

Data were recorded mainly by prospective protocols created and used continuously from the beginning of the study. As a supplement to the protocols, in a minority of cases, an active retrospective search had to be performed and the medical records of these patients were reviewed. An HVOT letter matching chart at a distance of 3 metres was used, with a 75\% criterion for testing visual acuity. A shorter distance was used if VA was 0.3 or less in order to have at least eight optotypes to identify in each row. Optical correction with spectacles and contact lenses for distance was used during testing. The visual acuity of the better eye was recorded and geometric mean values were calculated. The cohort was compared with a national register recorded by low vision clinics in order to minimise the number of missed cases.

The cohort consisted of 71 children with bilateral congenital cataracts. Two children died because of multiple malformations, five children could not cooperate during visual acuity examination because of severe mental retardation, one child could not be contacted for follow up because of emigration, and in two cases the medical recordings were missing. A total of 39 children ( 21 boys and 18 girls) underwent cataract surgery before age 12 . Three children were operated on after age 12 and were consequently excluded from the study. Of the operated patients a total of 20 children suffered from total bilateral congenital cataracts and 19 from partial cataracts. One patient with partial cataracts who underwent monocular surgery was excluded from the study because the surgery resulted in amaurosis, and the number of children analysed was consequently 38. Another 19 children (11 boys and eight girls) with partial cataracts did not qualify for surgery and were therefore not operated on at all.

Patient age at the time of cataract surgery varied from 2 days to 9 years, with a median age of 119 days. The percentage of eyes operated on at the age of 100 days or before was $46 \%$. Twenty eight per cent were operated on after 1 year of age.

The number and types of coexisting systemic abnormalities in the cohort are shown in Table 2. Factors that may influence VA are listed in Table 3. (It should be noted that the eyes with coexisting ocular abnormalities in no cases represented the better eyes.)

The visual results from children operated on before 7 weeks were statistically compared with patients operated on between 7 weeks and 1 year, using parametric as well as nonparametric methods.

\section{RESULTS}

Almost half of the children studied (47\%) demonstrated a monocular VA of 0.4 or higher during the study period and $16 \%(6 / 38)$ achieved a VA of 1.0 or better. Only one patient remained legally blind (VA $<0.05$ ) at 10 years of age after surgery.

Table 2 Coexisting systemic abnormalities (number of cases defined as partial cataracts appear in parentheses)

\begin{tabular}{ll}
\hline Abnormalities & No $\%$ \\
\hline Systemic: & $3(1)$ \\
Trisomy 21 & $1(1)$ \\
Congenital hypothyroidism & 2 \\
Lowe's syndrome & 1 \\
Subclinical rubella & $2(2)$ \\
Undefined retarded development & $1(1)$ \\
Diabetes mellitus & \\
Total & \\
& \\
Other: & $1(1)$ \\
DAMP, autism & $2(1)$ \\
Cleft palate & $1(1)$ \\
Cerebral palsy & $1(1)$ \\
Tourette's syndrome & 1 \\
Epilepsy & $1(1)$ \\
Rheumatoid arthritis* & $1(1)$ \\
Asberger's syndrome & 1 \\
Coeliac disease & \\
Total & \\
\hline *Coexisting with the case of congenital hypothyroidism. \\
\hline
\end{tabular}


Table 3 Potential factors affecting visual acuity in relation to age at surgery for type of cataract (number of cases defined as partial cataracts appear in parentheses)

\begin{tabular}{lllllllll}
\hline & Glaucoma & PCO & Nystagmus & $\begin{array}{l}\text { Secondary } \\
\text { IOL }\end{array}$ & $\begin{array}{l}\text { Ocular } \\
\text { abnormality }\end{array}$ & $\begin{array}{l}\text { Systemic } \\
\text { disease }\end{array}$ & $\begin{array}{l}\text { Heriditary } \\
\text { factors }\end{array}$ & Subjects \\
\cline { 2 - 9 } Age at surgery & No & No & No & No & No & No & No & No \\
\hline$<7$ weeks & $2(1)$ & $10(2)$ & $10(2)$ & 0 & 1 & 4 & $11(2)$ & $15(2)$ \\
7 weeks-1 year & $4(1)$ & $8(4)$ & $9(3)$ & $1(1)$ & $1(1)$ & 1 & $4(2)$ & $13(6)$ \\
$>1$ year & 0 & $6(6)$ & $1(1)$ & $7(7)$ & $1(1)$ & $5(5)$ & $4(4)$ & $10(10)$ \\
Total & $6(2)$ & $24(12)$ & $20(6)$ & $8(8)$ & $3(2)$ & $10(5)$ & $19(8)$ & $38(18)$ \\
\hline
\end{tabular}
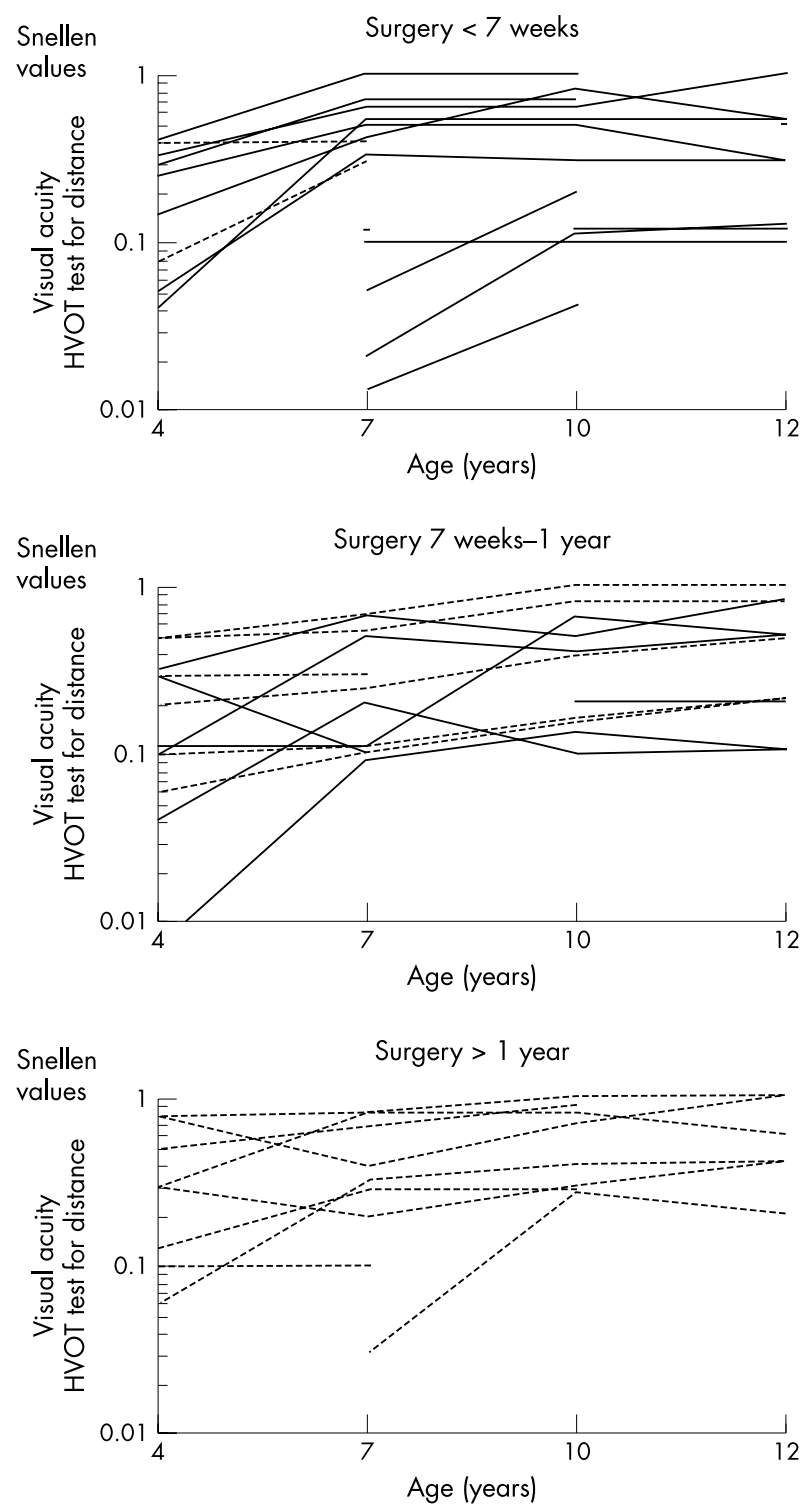

Figure 1 Individual visual acuity development in the better eye in relation to age at surgery and type of cataract. Total cataracts are marked with a continuous black line and partial with a broken line. The VA development curves are discontinuous in a small number of cases because of lack of cooperation during the examination. Three patients operated on $<7$ weeks whose first examined VA was below 0.1 at the age of 7 years all suffered from systemic abnormalities: Lowe's syndrome, undefined retarded development and trisomy 21 .

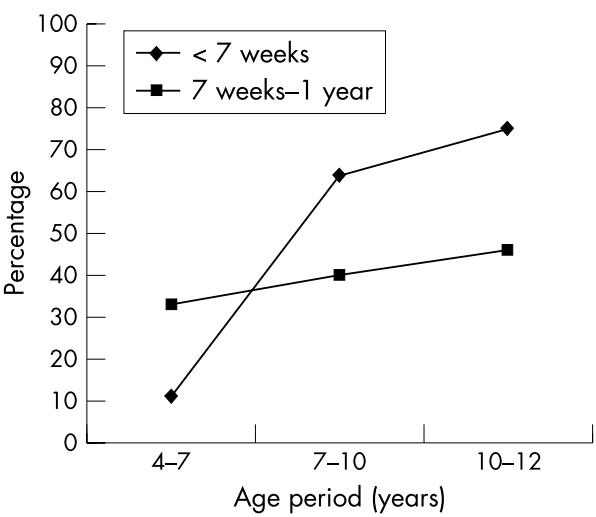

Figure 2 Stabilisation in VA development in relation to age at surgery. If no improvement in VA level was shown between the ages at which the measurements were taken, or if VA remained at the same level or below, development was defined as stabilised.

Individual visual acuity development in relation to age at surgery and type of cataract is shown in Figure 1. The children operated on after 1 year of age all had partial cataracts and exhibited higher levels of VA in a majority of cases.

VA developmental curves were analysed with the purpose of investigating the relation between age at surgery and stabilisation of VA development (Fig 2). A disparity between the two earliest operated categories was found. In the earliest group ( $<7$ weeks) $64 \%$ stabilised after 7 years of age. Corresponding analysis of the patients who had undergone surgery between 7 weeks and 1 year of age resulted in $40 \%$. After 10 years of age $75 \%$ in the earliest operated group had ceased to improve, whereas only $46 \%$ of patients operated on between 7 weeks and 1 year had stabilised.

The mean VA at 4 and 12 years in relation to age at surgery and type of cataract is shown in Table 4. No total cataracts were operated on after 1 year of age. On the other hand, only two cases of partial cataracts underwent surgery before 7 weeks of age and therefore no mean values were calculated. A difference in mean VA of total cataracts at 4 years of age was shown when comparing surgery within the first 7 weeks of life with surgery between 7 weeks and 1 year of age, VA 0.15 versus 0.08 . Despite this finding, all children with total cataracts reached an equal mean VA level at 12 years of age independent of age at surgery. However, no statistically significant difference between the group of children operated on before 7 weeks and the group operated on between 7 weeks and 1 year could be proved.

The majority of the patients with partial cataracts had a higher level of VA at the ages of 4 and 12 compared to the group with total cataracts. The mean VA calculations in the group with partial cataracts resulted in values up to 0.52 at 12 years of age. 
Table 4 Mean VA calculated for the better eye at 4 and 12 years of age in relation to age at surgery and type of cataract (number of cases defined as partial cataracts appear in parentheses)

\begin{tabular}{|c|c|c|c|c|c|}
\hline \multirow[b]{3}{*}{ Age at surgery } & \multirow{2}{*}{\multicolumn{2}{|c|}{$\frac{\text { Partial }}{\text { Mean VA }}$}} & \multirow{2}{*}{\multicolumn{2}{|c|}{$\frac{\text { Total }}{\text { Mean VA }}$}} & \multirow[b]{3}{*}{ Subjects (n) } \\
\hline & & & & & \\
\hline & 4 years & 12 years & 4 years & 12 years & \\
\hline$<7$ weeks & - & - & 0.15 & 0.27 & $15(2)$ \\
\hline 7 weeks-1 year & 0.21 & 0.44 & 0.08 & 0.26 & $13(6)$ \\
\hline $\begin{array}{l}>1 \text { year } \\
\text { Total }\end{array}$ & 0.26 & 0.52 & - & - & $\begin{array}{l}10(10) \\
38(18)\end{array}$ \\
\hline
\end{tabular}

\section{DISCUSSION}

In a study of continuous VA development by Schulz, all subjects were operated on before 6 months of age and the author concluded that VA development increased up to school age. ${ }^{10}$ This finding correlates with the group of children operated on before 7 weeks in our study although we noted that $25 \%$ were still improving after age $10 .^{29}$ That $54 \%$ of the children operated on between 7 weeks and 1 year were also still improving in VA after age 10 was unexpected. However, a study of a normal population in Sweden by Frisén and Frisén in 1981 showed continuous development of VA until 25 years of age and a gradual decline thereafter. ${ }^{30}$

Apart from age several other important covarying factors and conditions affect visual outcome, such as correction of refraction, presence of intraocular lenses, postoperative complications, nystagmus, and coexisting ocular as well as systemic abnormalities. Their impact is difficult to estimate in the present study. Compliance with amblyopia therapy probably has less effect on the results than other factors since the VA values represent the better eye. Table 3 shows that in the group of children operated on within 7 weeks, systemic diseases and hereditary factors are more common than in the other groups. These factors imply that state of health is lower in this group, which can lead to an underestimation of the gains of early surgery. The remaining covarying factors in Table 3 are otherwise represented to the same extent in the two categories of children operated on within the first year of life.

Surgical intervention before 7 weeks on total cataracts implied no improvement in VA at 12 years of age, which was unexpected but in accordance with a study by Bradford et al in 1994. ${ }^{27}$ One possible explanation could be that some of the total cataracts discovered after 8 weeks of age were actually initial partial and progressive cataracts. Another explanation could be that visual rehabilitation after surgery was perhaps less successful in our cohort and consequently concealed the positive effects of early surgery. However, if this was the case our study would have most likely resulted in overall lower VA levels compared to those reported by Gelbart et al, ${ }^{6}$ which indicated a relation between surgery before 8 weeks and good visual outcome, but the VA levels in our study were similar. Despite this finding, the mean VA level at age 4 was higher for those who underwent surgery before 7 weeks of age.

Early surgery within the first weeks of life is on one hand described as preferable, ${ }^{4-68181921}$ yet has on the other hand been proposed to be a risk factor for postoperative complications such as glaucoma. ${ }^{31}{ }^{32}$ The reported incidence of postoperative glaucoma after the 1970s is higher than before this decade. ${ }^{33}$ However, the literature does not provide a conclusive explanation for the seeming increase in aphakic glaucoma in these children. ${ }^{35}$

The VA measured at 12 years of age in this study corresponds to the results of several studies on congenital and infantile bilateral cataracts performed during the past two decades. They report a VA of 0.5 or higher for over $40 \%$ of the subjects studied. ${ }^{3671012132736-38}$ Two cases of total cataracts achieved a VA of 1.0 and 0.8 , respectively, and both underwent surgery before 4 months of age. The range of age at surgery regarding total cataracts varied from 2 days to 7.5 months. One subject with total cataracts remained legally blind at age 10. This patient suffered from a systemic abnormality (Lowe's syndrome). In the present study $21 \%$ of the patients achieved a VA of $\geqslant 1.0$ on the better eye at either 10 or 12 years of age, as compared to $98 \%$ in a normal population. ${ }^{39}$ The visual results have been calculated on geometric means ${ }^{40}$ of VA of the better eye, which implies that the reported VA should be regarded as a minimum level of achievable outcome.

In this study we have not focused on the treatment after surgery as much as on the actual timing of the surgical intervention in an attempt to understand the significance of early surgery for bilateral cataracts. Despite the fact that the present study is unique regarding length of follow up and the geographical basis of the cohort, the combination of low patient number and numerous covarying factors made it impossible to statistically prove the favourable effect of young age at surgery ( $<7$ weeks). Like Bradford et al in 1994, ${ }^{27}$ we failed to prove that surgery during the very first weeks of life affects VA on a long term basis. On the other hand, there is a possibility that the influence of age at surgery in bilateral cataracts is limited before the age of 3 or 4 months. The characteristics of the data in our cohort did not allow further analysis regarding outcome according to this age limit. Increased knowledge about the detrimental effects of competitive inhibition ${ }^{41}$ makes it natural to consider that there may be a difference between unilateral and bilateral cataracts in the length of the latent period of visual development. If this is the case, there is a possibility that the length of the critical period also differs

In conclusion, approximately $50 \%$ of the subjects received a VA rating of 0.4 or higher, corresponding to previous studies conducted during the past two decades. Visual acuity improves greatly after school age, especially for those who undergo surgery between the ages of 7 weeks and 1 year. VA prognoses for partial cataracts are positive compared to those for total, reaching a mean of approximately 0.5 at 12 years of age. Surgery within the first 7 weeks of life initially results in a more rapid development of VA compared with the group operated on between 7 weeks and 1 year. However, no statistically significant difference in VA results among these groups could be proved.

\section{ACKNOWLEDGEMENTS}

This study was supported by the Swedish Medical Research Council (grant no 02226), Kronprinsessan Margaretas Arbetsnämnd, Handlanden H. Svensson Foundation, Margit Thyselius Foundation, De Blindas Vänner, Sigvard and Marianne Bernadotte Foundation, Wilhelm and Martina Lundgren Science Foundation, the Mayflower Charity Foundation for Children, Sunnerdahl Handikappfond, and the Ahrnberg Foundation. 


\section{Authors' affiliations}

G Magnusson, M Abrahamsson, J Sjöstrand, Göteborg University, Sweden

\section{REFERENCES}

1 Beller R, Hoyt CS, Marg E, et al. Good visual function after neonatal surgery for congenital monocular cataracts. Am J Ophthalmol 1981;91:559-65.

2 Lewis T, Maurer D, Brent H. Effects on perceptual development of visual deprivation during infancy. Br J Opthalmol 1986;70:214-20.

3 Pratt-Johnson J, Tillson G. Visual results in congenital cataract surgery performed under the age of 1 year. Can J Ophthalmol 1981;16:19-21.

4 Kugelberg $\mathrm{U}$. Visual acuity following treatment of bilateral congenital cataracts. Doc Ophthalmol 1992;82:21 1-5.

5 Rogers GL, Tishler CL, Tsou BH, et al. Visual acuities in infants with congenital cataracts operated on prior to 6 months of age. Arch Ophthalmol 1981;99:999-1003.

6 Gelbart SS, Hoyt CS, Jastrebski G, et al. Long-term visual results in bilateral congenital cataracts. Am J Ophthalmol 1982;93:615-21.

7 Lorenz B, Wörle J. Visual results in congenital cataract with the use of contact lenses. Albrecht von Graefes Arch Klin Ophthalmol 1991;229:123-32

8 Birch E, Stager D, Wright W. Grating acuity development after early surgery for congenital unilateral cataract. Arch Ophthalmol 1986:104:1783-7.

9 Grossman SA, Peyman GA. Long-term visual results after pars plicata lensectomy-vitrectomy for congenital cataracts. Br J Ophthalmol 1988;72:601-6.

10 Schulz E. Visual development and refractive changes in congenital cataract. Eur J Implant Ref Surg 1990;2:253-6.

11 Jaafar MS, Robb RM. Congenital anterior polar cataract: a review of 63 cases. Ophthalmology 1984;91:249-54

12 Wright KW, Christensen LE, Noguchi BA. Results of late surgery for presumed congenital cataracts. Am J Ophthalmol 1992;1 14:409-15.

13 Robb RM, Petersen RA. Outcome of treatment for bilateral congenital cataracts. Ophthalmic Surg 1992;23:650-6.

14 Dahan E, Salmenson BD. Pseudoaphakia in children: Precautions, technique, and feasibility. J Cataract Refract Surg 1990;16:75-82.

15 Hiles DA, Wallar PH. Visual results following infantile cataract surgery. Int Ophthalmol Clin 1977;17:39-45.

16 Francis PJ, lonides A, Berry V, et al. Visual outcome in patients with isolated autosomal dominant congenital cataract. Ophthalmology 2001;108:1104-8.

17 Lloyd IC, Goss-Sampson M, Jeffrey BG, et al. Neonatal cataract: aetiology, pathogenesis and management. (Review) Eye 1992;6:184-96.

18 Birch EE, Swanson WH, Stager DR, et al. Outcome after very early treatment of dense congenital unilateral cataract. Invest Ophthalmol Vis Sci 1993;34:3687-99.

19 Birch EE, Stager DR. Prevalence of good visual acuity following surgery for congenital unilateral cataract. Arch Ophthalmol 1988;106:40-3.

20 Birch EE, Stager D, Leffler J, et al. Early treatment of congenital unilateral cataract minimizes unequal competition. Invest Ophthalmol Vis Sci 1998; 39:1560-6.
21 Birch EE, Stager DR. The critical period for surgical treatment of dense congenital unilateral cataract. Invest Opthalmol Vis Sci 1996;37:1532-8.

22 Mayer DL, Dobson V. Visual acuity development in infants and young children assessed by operant preferential looking. Vis Res 1982;22:1141-51

23 Van Hof-van Duin J, Mohn G. The development of visual acuity in normal fullterm and preterm infants. Vis Res 1986;26:909-16.

24 Teller DY. First glances: the vision of infants. The Friedenwald lecture. (Review) Invest Ophthalmol Vis Sci 1997;38:2183-203.

25 Maurer D, Lewis TL. Visual acuity: the role of input in inducing postnatal change. Clin Neurosci Res 2001;1:239-47.

26 Taylor D. The Doyne lecture. Congenital cataract: the history, the nature, and the practice. Eye 1998;12:9-36.

27 Bradford GM, Keech RV, Scott WE. Factors affecting visual outcome after surgery for bilateral congenital cataracts. Am J Ophthalmol 1994; 117:58-64.

28 Yamamoto $M$, Dogru $M$, Nakamura $M$, et al. Visual function following congenital cataract surgery. Jpn J Ophthalmol 1998;42:411-16.

29 Abrahamsson M, Sjöström A, Sjöstrand J. Delayed vision development in 3 children with congenital cataract. Klin Monatsbl Augenheilkd 1999;215:91-4

30 Frisén $L$, Frisén $M$. How good is normal visual acuity? A study of letter acuity thresholds as a function of age. Albrecht Von Graefes Arch Klin Exp Ophthalmol 1981;215:149-57.

31 Magnusson G, Abrahamsson M, Sjöstrand J. Glaucoma following congenital cataract surgery: an 18-year longitudinal follow-up. Acta Ophthalmol Scand. 2000;78:65-70

32 Mills M, Robb R. Glaucoma following childhood cataract surgery. J Pediatr Ophthalmol Strabismus 1994;31:355-60.

33 Johnson CP, Keech RV. Prevalence of glaucoma after surgery for PHPV and infantile cataracts. J Paediatr Ophthalmol Strabismus 1996:33:14-17.

34 François J. Late results of congenital cataract surgery. Ophthalmology 1979;86:1586-98.

35 Russell-Eggitt I, Zamiri P. Review of aphakic glaucoma after surgery for congenital cataract. (Review) J Cataract Refract Surg 1997;23(Suppl 1):664-8.

36 Shapiro A, Duval EJ. Visual functions following bilateral surgery of congenital cataracts in children. J Pediatr Ophthalmol Strabismus 1979; 16:176-9.

37 Parks MM. Visual results in aphakic children. Am J Ophthalmol 1982;94:441-9.

38 Leseur LC, Arné JL, Chapotot EC, et al. Visual outcome after paediatric cataract surgery: is age a major factor? $\mathrm{Br} J$ Ophthalmol 1998:82:1022-5.

39 Ohlsson J, Villarreal G, Sjöström A, et al. Visual acuity, residual amblyopia and ocular pathology in a screened population of 12-13-year-old children in Sweden. Acta Ophthalmol Scand 2001;79:589-95.

40 Moseley MJ, Jones HS. Visual acuity: calculating appropriate averages. Acta Ophthalmol Scand 1993;71:296-300

41 Harwerth RS, Smith EL 3rd, Paul AD, et al. Functional effects of bilatera form deprivation in monkeys. Invest Ophthalmol Vis Sci 1991;32:2311-27 